\title{
Middle Ear Adenocarcinoma
}

National Cancer Institute

\section{Source}

National Cancer Institute. Middle Ear Adenocarcinoma. NCI Thesaurus. Code C6848.

A rare adenocarcinoma that arises from the middle ear. 